\title{
A New Explanation of Heterogeneous Human Capital and Trade
}

\author{
Cheng-Te Lee ${ }^{1} \&$ Yao-Hsuan Wang ${ }^{1}$ \\ ${ }^{1}$ Department of International Trade, Chinese Culture University, Taipei, Taiwan \\ Correspondence: Cheng-Te Lee, Department of International Trade, Chinese Culture University, No. 55, \\ Hwa-Kang Road, Yang-Ming-Shan, Taipei City 11114, Taiwan. Tel: 886-2-2861-0511 ext. 35135. E-mail: \\ lzd4@faculty.pccu.edu.tw
}

Received: May 25, 2012

Accepted: June 24, $2012 \quad$ Online Published: July 5, 2012

doi:10.5539/ijef.v4n8p93

URL: http://dx.doi.org/10.5539/ijef.v4n8p93

\begin{abstract}
This paper constructs a simple two-sector, competitive trade model with heterogeneous labor and considers two countries' differences in both diversities and means of human capital distributions. We prove that the distributions differences affect the comparative advantage through two channels including "the diversity effect" and "the mean effect". When the diversity effect dominates the mean effect, the country will have comparative advantages in the $S$-sector, and hence will lead to an expansion in the $S$-sector, vice versa.
\end{abstract}

Keywords: heterogeneous human capital, trade, the diversity effect, the mean effect

\section{JEL classification: F11}

\section{Introduction}

In recent years, the effects of heterogeneous human capital on the industrial structure and the pattern of trade (POT) of an economy have received considerable attention. Some earlier theoretical studies, for example, Roy (1951), Heckman and Sedlacek (1985) and Heckman and Honoré (1990), explore the relationship between heterogeneous workers and industrial structure. In addition, in order to account for the observation that a large volume of international trade takes place between rich countries with similar technologies and endowments, in their pioneering work, Grossman and Maggi (2000) argue that the distribution of human capital can matter for the pattern of comparative advantage and industrial structure. (Note 1)

The recent literature exploring the impact of heterogeneous human capital on trade includes Ishikawa (1996), Grossman and Maggi (2000), Grossman (2004), Bougheas and Riezman (2007), and Ohnsorge and Trefler (2007). First, Ishikawa (1996) stresses the role of aggregate human capital endowments in affecting comparative advantage and industrial structure. Although Ishikawa investigates the relationship between the distribution of human capital and trade, he ignores the effects of diversity of human capital on trade.

Next, Grossman and Maggi (2000) and Grossman (2004) prove that a country with less diverse human capital will have comparative advantage in passenger cars, industrial equipment and chemicals, produced by a supermodular technology (or by teams). In contrast, a country with a more diverse human capital will have comparative advantage in software and financial services produced by a submodular technology (or by individual efforts). Bougheas and Riezman (2007) demonstrate that the POT between two countries with identical aggregate human capital endowments depends on the properties of the distribution of human capital. Ohnsorge and Trefler (2007) consider each worker bringing two skills to the workplace (e.g., quantitative and communication skills) and point out that the second moments of the distributions of skills can affect comparative advantage. In sum, they argue that diversity of human capital plays an important role in determining the POT and industrial structure.

Whether the immigration policy will affect the pattern of comparative advantage and industrial structure of an economy or not is an interesting and important issue. Intuitively, government immigration policies will lead to a change in the distribution of human capital, which in turn will determine the POT and industrial structure. 
Table 1. Industrial Composition in Singapore, $1991 \& 2001$

\begin{tabular}{llll}
\hline Industrial Composition (\%) & 1991 & 2001 & Change (\%) \\
\hline Manufacturing & 28.2 & 18.8 & -33.3 \\
Commerce & 22.7 & 21.1 & -7.0 \\
Transport and Communication & 10.0 & 11.1 & +10.0 \\
Financial and Business Services & 10.7 & 17.2 & +37.8 \\
Community and Personal Services & 21.1 & 24.7 & +14.6 \\
Others & 7.3 & 7.1 & -2.7 \\
\hline
\end{tabular}

Source: MOM (2002) and Frost and Chiu (2003).

There is prominent evidence illustrating the impact of the immigration policy on the pattern of comparative advantage and industrial structure. Singapore successful immigration policies alter not only industrial structure but also the pattern of comparative advantage, and then improve Singapore's economic development. Table 1 reveals Singapore's industrial composition in 1991 and 2001. It is not difficult to find that Singapore's industrial structure has been translated from being based on the manufacturing sector to the financial and personal services sectors. Namely, two sectors referring to financial and business services along with community and personal services have grown significantly in the 1990s. In addition, many empirical studies show that, in Singapore, the volume of services trade has also increased rapidly in the 1990s, for example, Blomqvist (2004), Kee (2009) and Wong et al. (2009). At the same time, we observe that Singapore's main economic strategy is based on attracting foreign skilled labor. To reach this goal, Singapore government liberalizes the immigration policies, as addressed by Yeoh (2007). Table 2 shows Singapore's foreign workers and indicates that those increase rapidly from 248,000 foreign workers constituting $16.1 \%$ of the total labor force in 1990 to 612,200 foreign workers constituting $29.2 \%$ of the total labor force in 2000. Furthermore, Piper (2004) and Yeoh (2007) offer further that about 112,200 of these foreign workers fall under the category of skilled labor in 2000, that is, skilled workers account for $18.3 \%$ (which is equal to $112,200 / 612,200$ ) of Singapore's total foreign workers. More specification, we observe that Singapore's immigration policies alter the distribution of human capital (Table 2), and then lead to a change in the POT and industrial structure. As mentioned earlier, the industrial structure has translated from manufacturing sector using a supermodular technology (or by teams) to financial and personal services produced by a submodular technology (or by individual efforts). Therefore, this paper will provide an alternative explanation for the Singapore case addressed above.

Table 2. Foreign Workers in Singapore

\begin{tabular}{llll}
\hline Year & Total Labor Force & Foreign Workers & Percent of Total Labor Force \\
\hline 1990 & $1,537,000$ & 248,000 & $16.1 \%$ \\
2000 & $2,094,800$ & 612,200 & $29.2 \%$
\end{tabular}

Source: see Yeoh (2007).

The existing literature ignores the impact of both aggregate human capital endowments and diversity on the pattern of comparative advantage and industrial structure. As a complement to the literature, we will construct a simple two-sector, competitive trade model with heterogeneous labor and consider two countries' differences in both diversities and means of human capital distributions. We prove that the distributions differences affect the comparative advantage and industrial structure through two channels. The first is "the diversity effect" whereby an increase in the diversity of human capital leads to an expansion in the submodular sector, and hence gives the economy more comparative advantages in the submodular goods. The second is "the mean effect" whereby a rise in the mean of human capital leads to an expansion in the supermodular sector, and hence gives the economy more comparative advantages in the supermodular goods. Building on these results, we are able to generate new predictions on the pattern of comparative advantage and industrial structure.

The remainder of this paper is organized as follow. Section 2 establishes the theoretical model. Section 3 analyzes the impact of the distribution differences in human capital on the comparative advantage. Section 4 concludes the paper.

\section{The Model}

The setup of this paper closely follows the trade model of Grossman and Maggi (2000), with heterogeneous 
human capital.

\subsection{The Setup of Model}

Consider the economy comprising two small open countries, $A$ and $B$, each with a fixed amount of workers (denoted by $L^{j}, \quad j \in\{A, B\}$ ). Each worker is endowed with a fixed level of talent $t$ which is assumed to be heterogeneous and perfectly observable to all the workers. Assume that the distribution of talent $t$ is a uniform distribution with probability density function $\phi^{j}(t)$ in country $j$ as shown below: (Note 2)

$$
\phi^{j}(t)=\left\{\begin{array}{l}
\frac{1}{b^{j}}, \quad \text { if } t \in\left[t_{\min }^{j}, t_{\max }^{j}\right], \\
0, \quad \text { otherwise, }
\end{array}\right.
$$

where $t_{\min }^{j}=\bar{t}^{j}-b^{j} / 2$ and $t_{\max }^{j}=\bar{t}^{j}+b^{j} / 2$. Obviously, the variables $t_{\min }^{j}$ and $t_{\max }^{j}$ are the minimum and maximum talent levels respectively and $\bar{t}^{j}$ is the average talent level. The variable $b^{j}$ represents the diversity of talent. The larger the variable $b^{j}$ is, the more diverse the distribution will be.

Suppose that both countries are similar in their production technologies and that there are two sectors in each country, sector $C$ with supermodular technology and sector $S$ with submodular technology. The production process for each sector involves two tasks, $x$ and $v$. The tasks are indivisible and each task is performed by exactly one worker. For simplicity, we let the production function of sector $C$ be $F_{C}\left(t_{x}, t_{v}\right)=\min \left\{t_{x}, t_{v}\right\}$, where the task $x$ (task $v$ ) is performed by a worker with talent $t_{x}$ (talent $t_{v}$ ), which implies that a pair of workers performs complementary tasks. Similarly, for simplicity, we assume that the production function of sector $S$ is $F_{S}\left(t_{x}, t_{v}\right)=\max \left\{t_{x}, t_{v}\right\}$, which indicates that the talent of the superior worker fully dominates the effective output and the workers toil on substitutive tasks. (Note 3)

In equilibrium, the $C$ sector employs workers with similar abilities, i.e., "skill-clustering", and the $S$ sector attracts the most-talented and least-talented workers, i.e., "cross-matching", as proved by Grossman and Maggi (2000). We define that, in the $C$ sector, the variables $\hat{t}^{j}$ and $m^{j}\left(\hat{t}^{j}\right)=2 \bar{t}^{j}-\hat{t}^{j}$ represent the talent levels of the least-talented and most-talented workers respectively. Consequently, total outputs of good $C$ and good $S$ (denoted by $Y_{C}^{j}$ and $Y_{S}^{j}$ respectively) can be obtained as follows:

$$
\begin{gathered}
Y_{C}^{j}=L^{j} \int_{\hat{t}^{j}}^{m^{j}\left(\hat{t}^{j}\right)} F_{C}(t, t) \phi^{j}(t) d t=\frac{L^{j} \bar{t}^{j}}{b^{j}}\left(\bar{t}^{j}-\hat{t}^{j}\right), \\
Y_{S}^{j}=L^{j} \int_{t_{\min }^{j}}^{\hat{t}^{j}} F_{S}\left[t, m^{j}(t)\right] \phi^{j}(t) d t=\frac{L^{j}}{2 b^{j}}\left(\frac{b^{j}}{2}-\bar{t}^{j}+\hat{t}^{j}\right)\left(\frac{b^{j}}{2}+3 \bar{t}^{j}-\hat{t}^{j}\right) .
\end{gathered}
$$

By combining equations (1) with (2) and eliminating the variable $\hat{t}^{j}$, we can derive the production possibility frontier of country $j$ as shown below:

$$
Y_{S}^{j}=\frac{L^{j}}{2}\left(\frac{1}{2}-\frac{1}{L^{j} \bar{t}^{j}} Y_{C}^{j}\right)\left(\frac{b^{j}}{2}+2 \bar{t}^{j}+\frac{b^{j}}{L^{j} \bar{t}^{j}} Y_{C}^{j}\right) .
$$

Hence, the marginal rate of transformation $\left(\mathrm{MRT}^{j}\right)$ can be calculated as follows:

$$
\mathrm{MRT}^{j}=-\frac{\partial Y_{S}^{j}}{\partial Y_{C}^{j}}=1+\frac{b^{j}}{L^{j} \bar{t}^{j^{2}}} Y_{C}^{j} .
$$

Assume that preferences in the countries $A$ and $B$ are identical and homothetic. Therefore, the competitive, free-trade equilibrium maximizes the national aggregate output at a given terms of trade, $p$, which represents the relative price of good $C$.

\subsection{Free Trade Equilibrium}

In free-trade equilibrium, the equilibrium condition $\left(p=\mathrm{MRT}^{j}\right)$ holds and then substituting equation (4) into the equilibrium condition can get:

$$
Y_{C}^{j}=\frac{L^{j} \bar{t}^{j^{2}}}{b^{j}}(p-1)
$$

By substituting equation (5) into equation (3), we obtain: 


$$
Y_{S}^{j}=\frac{L^{j} \bar{t}^{j^{2}}}{2 b^{j}}\left[\left(1+\frac{b^{j}}{2 \bar{t}^{j}}\right)^{2}-p^{2}\right] .
$$

From equations (5) and (6), we can find the relative equilibrium output of country $j$ as shown below:

$$
\frac{Y_{S}^{j}}{Y_{C}^{j}}=\frac{\left(1+\frac{b^{j}}{2 \bar{t}^{j}}\right)^{2}-p^{2}}{2(p-1)} .
$$

From equation (7), we find that, in addition to $p$, the factors affecting the relative equilibrium output include $b^{j}$ and $\bar{t}^{j}$. That is to say, the talent distribution differences including $b^{j}$ and $\bar{t}^{j}$ can affect the relative equilibrium output and then matter for the comparative advantage. Therefore, before proceeding any further, it would be helpful to discuss the economic intuition of the talent diversity $\left(b^{j}\right)$ and mean $\left(\bar{t}^{j}\right)$ from the aspect of comparative advantage. Obviously, a larger value of $b^{j}$ represents more diversity of the talent distribution, and hence gives the economy more comparative advantages in the $S$-sector, called the diversity effect by Grossman and Maggi (2000). On the contrary, since the mean $\left(\bar{t}^{j}\right)$ represents the average talent level, the greater the mean is, the more the total talent employed in the $C$-sector is, implying more comparative advantage in the $C$-sector, called the mean effect hereafter. (Note 4)

\section{Comparative Advantage}

In this section, we will explore how the diversity effect and the mean effect affect the pattern of comparative advantage and industrial structure. For this purpose, suppose that the relationship of the diversities of talent between countries $A$ and $B$ is $b^{A}=\alpha b^{B}$ and $\alpha>0$. In addition, we also assume that the relationship of the average talent levels of countries $A$ and $B$ is $\bar{t}^{A}=\beta \bar{t}^{B}$ and $\beta>0$. Obviously, the variable $\alpha$ can capture the diversity effect and the variable $\beta$ can capture the mean effect. Therefore, from equation (7), we can obtain the relative equilibrium outputs of countries $A$ and $B$ as follows:

$$
\frac{Y_{S}^{A}}{Y_{C}^{A}}=\frac{\left(1+\frac{\alpha b^{B}}{2 \beta \bar{t}^{B}}\right)^{2}-p^{2}}{2(p-1)}, \quad \frac{Y_{S}^{B}}{Y_{C}^{B}}=\frac{\left(1+\frac{b^{B}}{2 \bar{t}^{B}}\right)^{2}-p^{2}}{2(p-1)} .
$$

Equation (8) shows that whether country $A$ 's equilibrium output ratio of $S$ with respect to $C$ is larger than that of country $B$ or not depends on both the diversity effect $(\alpha)$ and the mean effect $(\beta)$. The results will be derived under three cases: (1) $\alpha>\beta$, (2) $\alpha<\beta$ and (3) $\alpha=\beta$.

Case 1: $\alpha>\beta$

Obviously, Case 1 implies that the diversity effect is larger than the mean effect. From equation (8), we have:

$$
\frac{Y_{S}^{A}}{Y_{C}^{A}}>\frac{Y_{S}^{B}}{Y_{C}^{B}} .
$$

Equation (9) indicates that country $A$ 's equilibrium output ratio of $S$ with respect to $C$ is larger than that of country $B$, and thus induces higher comparative advantage in $S$-sector for country $A$. While the diversity effect is shown in the literature to be better for the $S$-sector than for the $C$-sector, we prove that if the diversity effect dominates the mean effect, the economy will have comparative advantages in the $S$-sector, and hence will lead to an expansion in the $S$-sector.

Case 2: $\alpha<\beta$

Case 2 reveals that the diversity effect is smaller than the mean effect. Again, from equation (8), we get:

$$
\frac{Y_{S}^{A}}{Y_{C}^{A}}<\frac{Y_{S}^{B}}{Y_{C}^{B}} .
$$

Equation (10) proves that the relative equilibrium output of country $A$ is smaller than that of country $B$, and hence leads to higher comparative advantage in $C$-sector for country $A$. Namely, if the mean effect dominates the diversity effect, the economy will have comparative advantages in the $C$-sector, and then the $C$-sector will expand.

Case 3: $\alpha=\beta$ 
Finally, Case 3 implies that the diversity effect is equal to the mean effect. From equation (8), we obtain:

$$
\frac{Y_{S}^{A}}{Y_{C}^{A}}=\frac{Y_{S}^{B}}{Y_{C}^{B}} .
$$

Equation (11) shows that country $A$ 's equilibrium output ratio of $S$ with respect to $C$ is equal to that of country $B$. That is to say, if the diversity effect is equal to the mean effect, then the differences of talent distribution will not affect the pattern of comparative advantage and industrial structure.

As analyzed earlier, we claim that the impact of the talent distribution differences in human capital on the comparative advantage and industrial structure depends on not only the diversity effect but also the mean effect. In sum, the results including Case 1, Case 2 and Case 3 can be summarized as below:

Proposition 1. When the diversity effect dominates the mean effect, the country will have comparative advantages in the S-sector. On the contrary, when the mean effect dominates the diversity effect, the country will have comparative advantages in the C-sector. Finally, if the diversity effect is equal to the mean effect, then the pattern of comparative advantage will be unaltered.

\section{Conclusion}

This paper sets up a simple two-sector, competitive trade model with heterogeneous labor to explore the impact of the differences of human capital distributions on the POT and industrial structure. We prove that the effects of the distributions differences on the pattern of comparative advantage and industrial structure depend on not only the diversity effect but also the mean effect. If the diversity effect dominates the mean effect, the economy will have comparative advantages in the $S$-sector, and hence will lead to an expansion in the $S$-sector, vice versa.

Immigration policy implications can be drawn from our results. Government immigration policy will alter the distribution of human capital. The distributions differences will affect the comparative advantage and industrial structure through two channels including the diversity effect and the mean effect. Therefore, Singapore's immigration policies attracting foreign skilled labor generate the result that the diversity effect dominates the mean effect, which in turn lead to an expansion in the financial and business services sector (i.e., the $S$-sector).

\section{Acknowledgements}

The paper has benefited from valuable suggestions given by participants in the 2011 Conference on International Trade and Business Administration. We are grateful to the editors and the anonymous referees for useful comments on the earlier version of this paper. Any remaining errors are our responsibility.

\section{References}

Blomqvist, H. C. (2004). Explaining trade flows of Singapore. Asian Economic Journal, 18, 25-43. http://dx.doi.org/10.1111/j.1467-8381.2004.00180.x

Bougheas, S., \& Riezman, R. (2007). Trade and the distribution of human capital. Journal of International Economics, 73, 421-433. http://dx.doi.org/10.1016/j.jinteco.2007.03.002

Brander, J. A. (1981). Intra-industry trade in identical commodities. Journal of International Economics, 11, 1-14. http://dx.doi.org/10.1016/0022-1996(81)90041-6

Costinot, A. (2009). On the origins of comparative advantage. Journal of International Economics, 77, 255-264. http://dx.doi.org/10.1016/j.jinteco.2009.01.007

Das, S. P. (2005). Vertical diversity, communication gap and equilibrium growth. Topics in Macroeconomics, 5 , Article 22. http://dx.doi.org/10.2202/1534-5998.1334

Davis, D. (1995). Intra-industry trade: A Heckscher-Ohlin-Ricardo approach. Journal of International Economics, 39, 201-226. http://dx.doi.org/10.1016/0022-1996(95)01383-3

Frost, S., \& Chiu, C. C. H. (2003). Labour relations and regbulation in Singapore: Theory and practice. Working Papers Series, 55, Southeast Asia Research Centre, City University of Hong Kong.

Grossman, G. M. (2004). The distribution of talent and the pattern and consequences of international trade. Journal of Political Economy, 112, 209-239. http://dx.doi.org/10.1086/379935

Grossman, G. M., \& Maggi, G. (2000). Diversity and trade. American Economic Review, 90, 1255-1275. http://dx.doi.org/10.1257/aer.90.5.1255

Heckman, J. J., \& Honoré, B. E. (1990). The empirical content of the Roy model. Econometrica, 58, 1121-1149. http://dx.doi.org/10.2307/2938303 
Heckman, J. J., \& Sedlacek, G. (1985). Heterogeneity, aggregation, and market wage functions: An empirical model of self-selection in the labor market. Journal of Political Economy, 93, 1077-1125. http://dx.doi.org/10.1086/261352

Ishikawa, J. (1996). Scale economies in factor supplies, international trade, and migration. Canadian Journal of Economics, 29, 573-594. http://dx.doi.org/10.2307/136251

Kee, H. L. (2009). Findlay-Grubert versus Rybczynski: Testing growth hypotheses in classic trade theories using Singapore's industries. The Journal of International Trade and Economic Development, 18, 443-486. http://dx.doi.org/10.1080/09638190903217727

Kremer, M. (1993). The O-Ring theory of economic development. Quarterly Journal of Economics, 108, 551-575. http://dx.doi.org/10.2307/2118400

Krugman, P. R. (1979). Increasing returns, monopolistic competition, and international trade. Journal of International Economics, 9, 469-479. http://dx.doi.org/10.1016/0022-1996(79)90017-5

Lee, C. T. (2009). The enlargement of an integrated economy and growth. Economics Bulletin, 29, 1499-1509.

Milgrom, P., \& Roberts, J. (1990). The economics of modern manufacturing: Technology, strategy, and organization. American Economic Review, 80, 511-528.

MOM. (2002). Report on Labour Force in Singapore, 2001. Singapore: Ministry of Manpower.

Ohnsorge, F., \& Trefler, D. (2007). Sorting it out: International trade and protection with heterogeneous workers. Journal of Political Economy, 115, 868-892. http://dx.doi.org/10.1086/523657

Piper, N. (2004). Gender and migration policies in Southeast and East Asia: Legal protection and socio-cultural empowerment of unskilled migrant women. Singapore Journal of Tropical Geography, 25, 216-231. http://dx.doi.org/10.1111/j.0129-7619.2004.00183.x

Roy, A. D. (1951). Some thoughts on the distribution of earnings. Oxford Economic Papers, 3, 135-146.

Wong, K. N., Tang, T. C., \& Fausten, D. K. (2009). Foreign direct investment and services trade: Evidence from Malaysia and Singapore. Global Economic Review, 38, 265-276. http://dx.doi.org/10.1080/12265080903157318

Yeoh, B. S. A. (2007). Singapore: Hungry for foreign workers at all skill levels. Migration Information Source (Migration Policy Institute). http://www.migrationinformation.org/profiles/display.cfm?id=570.

\section{Notes}

Note 1. The other theoretical papers, for example, Krugman (1979), Brander (1981), Davis (1995), and Costinot (2009), have also explained the observation.

Note 2. The similar specification of the probability density function can also be seen in Lee (2009).

Note 3. For the implications of the supermodular and submodular technologies, please also see Milgrom and Roberts (1990), Kremer (1993), Grossman and Maggi (2000) and Das (2005).

Note 4. Bougheas and Riezman (2007) point out that the mean of human capital distribution can be viewed as the aggregate endowment of human capital. 